\title{
Preparation and performance study of mixed metal oxide catalyst for catalytic removal of toluene
}

\author{
Hongbo Liu ${ }^{1,2,3,}$, Zhiyong Huang ${ }^{3, b}$, Wenhao Huang ${ }^{3, \mathrm{c}}$, Chong Li ${ }^{1,2,3, \mathrm{~d}}$ \\ ${ }^{1}$ School of Chemistry and Chemical Engineering, Beijing Institute of Technology, 100081 Beijing, China \\ 2 Print-rite Unicorn Image Products Co. Ltd. of Zhuhai, 519060 Zhuhai, China \\ ${ }^{3}$ School of Materials Science and Environment, Beijing Institute of Technology Zhuhai, 519088 Zhuhai, China
}

\begin{abstract}
As an important pollutant in VOCs, toluene has a serious impact on people's health and atmospheric environment. Mixed metal oxide catalyst was prepared by using hydrotalcite as precursor due to the characteristics of its unique composition and controllable structure. Thus the technical problems of difficult control of structure and high cost of nano catalyst were solved. The mixed metal oxide was used as catalyst for toluene removal and its catalytic performance was studied. The results show that the hydrotalcite precursor with good structure can be obtained by both co-precipitation and hydrothermal method. The well-structured precursor can be synthesized in the range of mole ratios of $0: 2: 1$ to 2:0:1 by different methods. When the reaction temperature is above $80{ }^{\circ} \mathrm{C}$, the reaction speed is fast and the crystalline of hydrotalcite is high. The removal efficiency of toluene by catalyst assisted low temperature plasma is better than that of single low temperature plasma. The best catalytic removal efficiency of toluene is $42.10 \%$, which is 1.8 times higher than that of single low temperature plasma. The order of catalytic performance of different catalysts and low temperature plasma for toluene removal is as follows: $\mathrm{Zn}-\mathrm{Mg}$ $\mathrm{Al}>\mathrm{Cu}-\mathrm{Mg}-\mathrm{Al}>\mathrm{Mg}-\mathrm{Al}>\mathrm{Co}-\mathrm{Mg}-\mathrm{Al}$.
\end{abstract}

\section{Introduction}

With the rapid progress of science and technology, the process of industrialization is accelerating, people's living standards are improving, and the environmental pollution caused by human activities is becoming more and more serious. At present, air pollution is getting worse. Human health is seriously threatened by industrial production, automobile exhaust and other gas pollutants, which has brought a very serious challenge to the world. Among these pollutions, the pollution of volatile organic compounds (VOCs) is becoming more and more serious. People gradually realize its harm. Various countries have formulated a series of laws and regulations to reduce the emission of VOCs. VOCs are harmful to human health and air environment. Most of VOCs are toxic and odorous, which can stimulate human eyes, nose and respiratory tract, and have toxic effects on heart, lung, liver and other internal organs and nervous system. Some VOCs can also cause acute or chronic poisoning of human body, which is carcinogenic and mutagenic [1]. On the other hand, under the condition of high temperature or ultraviolet radiation, VOCs can be cracked and produce active free radicals. A series of reactions occurred and resulted in secondary pollution [2]. At present, VOCs treatment methods can be divided into source control technology and post-processing technology. The post-processing technology can be divided into recovery technology and removal technology. Catalytic removal refers to the harmful components in the exhaust are converted into $\mathrm{CO}_{2}$ and $\mathrm{H}_{2} \mathrm{O}$ with the participation of catalyst. In the process of industrial waste gas removal, pollutants in a wide concentration range and multi-component pollutants can be removed cooperatively through the design and adjustment of catalyst components. At present, the catalysts used in VOCs catalytic removal can be divided into noble metal based and non-noble metal based catalysts [3, 4]. At present, the research focus on the design of mixed metal oxide catalysts with high activity, high stability and low cost compared with noble metal catalysts.

Hydrotalcite, also known as anionic clay or layered doubled hydroxide, is a kind of layered structure compound with exchangeable anions between layers [5]. Its structure is shown in Fig. 1. Compared with traditional catalysts, the hydrotalcite precursor derived mixed metal oxides not only have high specific surface area, but also have high dispersion of oxide grains, high strength, water resistance, corrosion resistance and sintering resistance. The main advantages of plasma treatment of VOCs are low operating temperature, high pollutant removal efficiency and non-toxic by-products. Dielectric barrier discharge (DBD) is an important method to generate plasma, which is a non-equilibrium gas discharge that takes place when insulating medium is inserted into discharge space [6].

\footnotetext{
* Corresponding author: 05065@,bitzh.edu.cn
} 


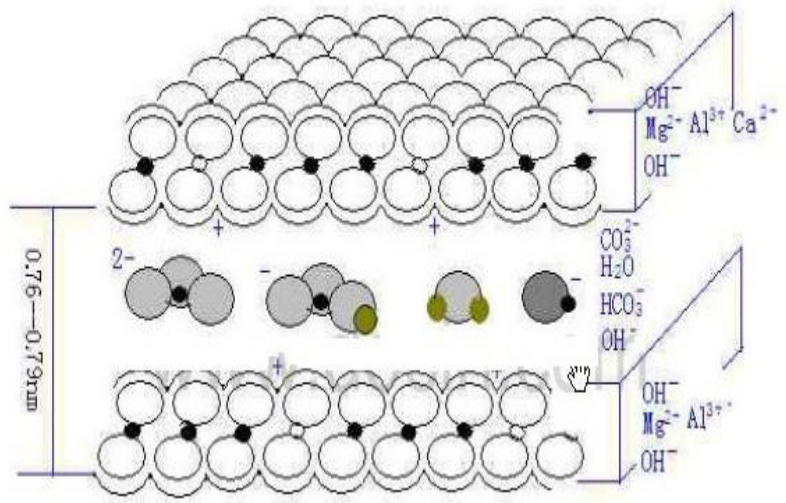

Fig. 1. Structure of hydrotalcite

In this paper, catalytic assisted low-temperature plasma technology was used. Hydrotalcite was used as the precursor to prepare mixed metal oxide, and its catalytic performance for the removal of toluene from VOCs was studied. The study has important practical significance and social benefits for the effective removal of toluene emissions, environmental protection and promotion of human health.

\section{Experimental}

\subsection{Synthesis of hydrotalcite precursor}

\subsubsection{Co-precipitation method}

Co-precipitation method was used to the synthesis of hydrotalcite precursor. $150 \mathrm{~mL}$ deionized water was added into a $1000 \mathrm{~mL}$ three port round bottom flask. The flask was then put into a $65^{\circ} \mathrm{C}$ water bath. Salt and alkali solution were dropped into a three the flask with the same dropping speed by using a separating funnel under stirring. The $\mathrm{pH}$ of the reaction system was kept stable by using $20 \%$ sodium hydroxide, and the mixed slurry was aged for $10 \mathrm{~h}$. After the reaction, the colloidal hydrotalcite was cooled, filtered and then washed with deionized water until no sulfate ion was detected (no precipitation by barium nitrate titration). The hydrotalcite was dried in the oven for $12 \mathrm{~h}$ at $85 \mathrm{oC}$. The dried block product was grinded, and the powder hydrotalcite was obtained by passing through 80 mesh sieve.

\subsubsection{Hydrothermal method}

The mixed slurry prepared in 2.1.1 above was put into a stainless steel autoclave, crystallize at $120^{\circ} \mathrm{C}$ for $6 \mathrm{~h}$. The colloidal hydrotalcite was then cooled, filtered, washed drying, grinded and sieved to obtain powdered hydrotalcite sample according to the above steps in 2.1.1.

\subsection{Preparation of mixed metal oxide catalyst}

The mixed metal oxide catalyst was prepared by the temperature programmed calcination technology. The mixed metal oxide catalyst was prepared by placing the hydrotalcite precursor in muffle furnace, and calcined at
$500{ }^{\circ} \mathrm{C}$ for $4 \mathrm{~h}$. The first paragraph after a section or subsection should not be indented; subsequent paragraphs should be indented by $5 \mathrm{~mm}$.

\subsection{Characterization of catalyst}

X-ray diffraction (XRD) patterns were determined using a Shimadzu 6100X diffractometer equipped with $\mathrm{Cu} \mathrm{Ka}$ radiation $(\lambda=1.5406 \AA$ ) operating with $40 \mathrm{kV}$ and $30 \mathrm{~mA}$. Infrared spectra (IR) were recorded using $\mathrm{KBr}$ pellet technique on a Brucker VECTOR22 spectrometer in $4000-450 \mathrm{~cm}^{-1}$.

\subsection{Test of catalytic behaviour}

Mixed metal oxide catalyst was used in the removal of toluene. $0.2 \mathrm{~g}$ catalyst was put into the plasma discharge area. The plasma voltage was set as $180 \mathrm{~V}$, and the discharge time was $10 \mathrm{~min}$. The toluene standard gas (concentration of $266 \mathrm{ppm}$ ) was introduced at the flow rate of $2000 \mathrm{~mL} / \mathrm{min}$ into the plasma reactor at room temperature. The content of toluene was determined by multi Rae (PID type) composite gas detector.

\section{Results and discussion}

\subsection{The effect of synthesis method}

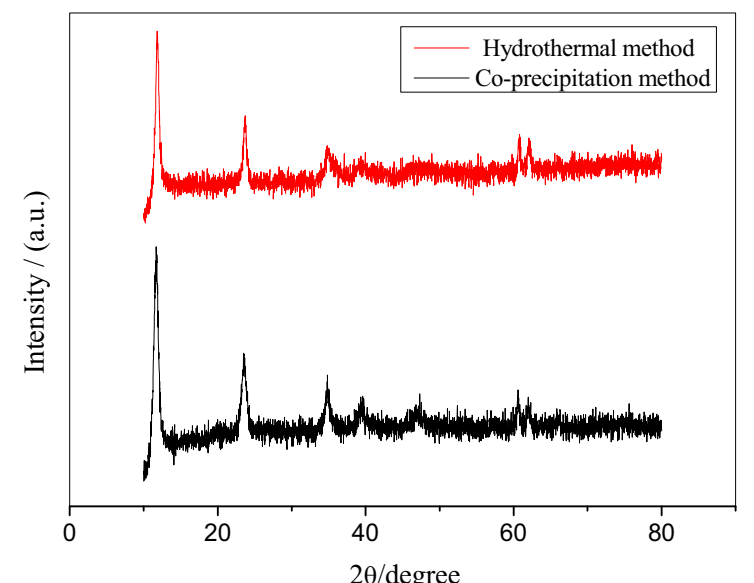

Fig. 2. $\mathrm{XRD}$ spectra for $\mathrm{Co} / \mathrm{Mg} / \mathrm{Al}$ hydrotalcite precursor prepared by different synthesis method

The XRD spectra of $\mathrm{Co} / \mathrm{Mg} / \mathrm{Al}$ precursor prepared by different synthesis method was shown in Fig.2. It can be seen from Fig. 2 that the $\mathrm{Co} / \mathrm{Mg} / \mathrm{Al}$ precursor prepared by different synthesis method show similar peaks at $11.5^{\circ}$, $23.1^{\circ}, 34.0^{\circ}, 38.6^{\circ}, 46.1^{\circ}, 59.2^{\circ}$ and $60.6^{\circ}$ respectively. Compared with the standard spectrum, it can be found that these peaks are characteristic diffraction peaks of hydrotalcite. The samples have stable baseline, sharp peak and no other peaks. It is indicated that the hydrotalcite precursor with good crystalline, single crystal phase and complete crystal can be obtained by different preparation methods. Compared with the two methods, co-precipitation method is simple, safe and easy to operate. And it also can be prepared in large quantities. Therefore, the co-precipitation method is used to prepare the hydrotalcite precursor. 


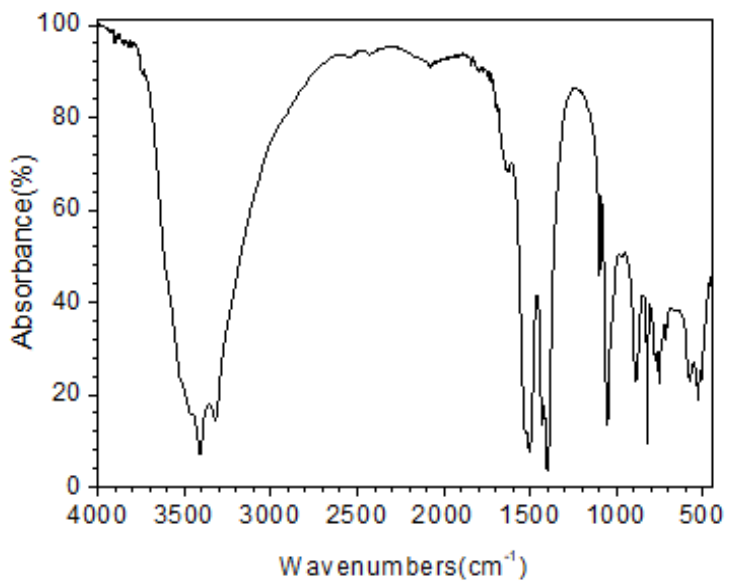

Fig. 3. FTIR spectrum for hydrotalcite precursor

The FTIR spectrum for hydrotalcite is shown in Fig. 3. The peaks with high intensity at 3404, 1512, 1407 and $1055 \mathrm{~cm}^{-1}$ are assigned to $-\mathrm{OH}$ in the layer, as well as $\mathrm{H}_{2} \mathrm{O}$ and $\mathrm{CO}_{3}{ }^{2-}$ between the hydrotalcite layers. It shows that the obtained hydrotalcite precursor has the typical hydrotalcite structure, which is in accordance with the XRD results.

\subsection{The effect of metal molar ratios}

XRD patterns of $\mathrm{Co} / \mathrm{Mg} / \mathrm{Al}$ hydrotalcite precursors prepared by different synthesis methods and different metal ratios was shown in Figure 4. Compared with the standard spectrum of hydrotalcite, it can be found that the samples show the characteristic diffraction peaks of hydrotalcite. Therefore, the $\mathrm{Co} / \mathrm{Mg} / \mathrm{Al}$ hydrotalcite precursors with good structure can be synthesized by different methods in the range of $\mathrm{Co} / \mathrm{Mg} / \mathrm{Al}$ molar ratio of $0: 2: 1$ to $2: 0: 1$.

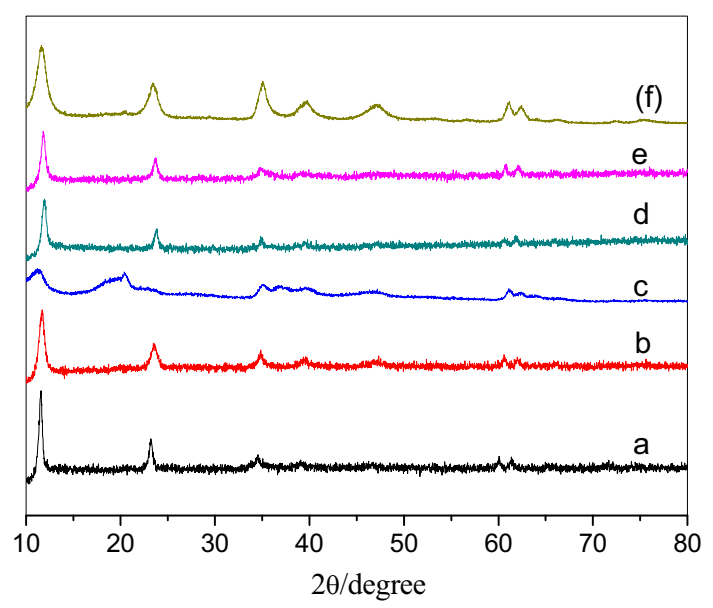

Fig. 4. XRD spectra for $\mathrm{Co} / \mathrm{Mg} / \mathrm{Al}$ hydrotalcite precursor prepared by different synthesis method and $\mathrm{Co} / \mathrm{Mg} / \mathrm{Al}$ molar ratios (a): $\mathrm{Co}_{2} \mathrm{Al}_{1}$-Co-precipitation; (b): $\mathrm{Co}_{1} \mathrm{Mg}_{1} \mathrm{Al}_{1}-\mathrm{Co}-$ precipitation; (c): $\mathrm{Mg}_{2} \mathrm{Al}_{1}-\mathrm{Co}$-precipitation; (d): $\mathrm{Co}_{2} \mathrm{Al}_{1}$ hydrothermal; (e): $\mathrm{Co}_{1} \mathrm{Mg}_{1} \mathrm{Al}_{1}$-hydrothermal; (f): $\mathrm{Mg}_{2} \mathrm{Al}_{1}$ hydrothermal

\subsection{The effect of reaction temperature}

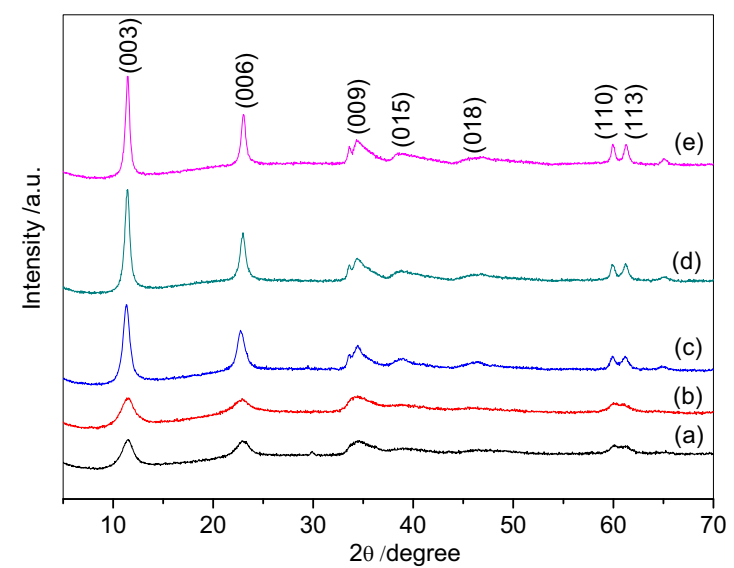

Fig. 5. XRD spectra for hydrotalcite precursor prepared by different temperature (a): $25^{\circ} \mathrm{C}$; (b): $60^{\circ} \mathrm{C} ;$ (c): $80^{\circ} \mathrm{C}$; (d): $90^{\circ} \mathrm{C} ;(\mathrm{e}): 100^{\circ} \mathrm{C}$

Fig. 5 shows the XRD spectra of the samples prepared at different reaction temperatures. It can be seen from Fig.5 that with the increase of crystallization temperature, the intensity of characteristic diffraction peak of hydrotalcite increased and the peak shape became sharp. It indicated that the layered structure of the sample gradually tended to be complete and the crystalline was increased. It can be seen that the formation of hydrotalcite was slow, and the complete layered structure cannot be formed in a short time when temperature below $80^{\circ} \mathrm{C}$. Therefore, the reaction temperature is $80-100{ }^{\circ} \mathrm{C}$.

\subsection{The effect of metal type on catalytic behaviour}

Table 1 shows the experimental data of toluene removal by low temperature plasma and different catalysts assisted low temperature plasma at room temperature. It can be found from table 1 that a single low temperature plasma has a certain removal effect on toluene at room temperature. The initial concentration of toluene was reduced from $266 \mathrm{ppm}$ to $226 \mathrm{ppm}$. When the low temperature plasma was assisted by mixed metal oxide catalyst, the concentration of toluene was significantly decreased and the catalytic performance was improved. For different kinds of mixed metal oxides, the order of catalytic activity is $\mathrm{Zn}-\mathrm{Mg}-\mathrm{Al}>\mathrm{Cu}-\mathrm{Mg}-\mathrm{Al}>\mathrm{Mg}-\mathrm{Al}>$ Co-Mg-Al. Among them, the catalytic efficiency of $\mathrm{Zn}$ $\mathrm{Mg}-\mathrm{Al}$ catalyst can reach $42.10 \%$, which is 1.8 times higher than that of single low temperature plasma. This shows that the catalyst assisted low-temperature plasma has a certain practical value in the catalytic removal of toluene. 
Table 1. Experimental data of toluene removal by low temperature plasma and different catalysts assisted low temperature plasma.

\begin{tabular}{|c|c|c|}
\hline $\begin{array}{c}\text { Initial concentration } \\
\text { of toluene (266ppm) }\end{array}$ & $\begin{array}{c}\text { Concentration of } \\
\text { toluene } \\
\text { (ppm) }\end{array}$ & $\begin{array}{c}\text { Conversion of } \\
\text { toluene } \\
(\%)\end{array}$ \\
\hline $\begin{array}{c}\text { Single low } \\
\text { temperature plasma }\end{array}$ & 226 & 15.04 \\
\hline $\begin{array}{c}\text { Mg-Al catalyst } \\
\text { assisted low } \\
\text { temperature plasma }\end{array}$ & 188 & 29.32 \\
\hline $\begin{array}{c}\text { Zn-Mg-Al catalyst } \\
\text { assisted low } \\
\text { temperature plasma }\end{array}$ & 154 & 42.11 \\
\hline $\begin{array}{c}\text { Cu-Mg-Al catalyst } \\
\text { assisted low } \\
\text { temperature plasma }\end{array}$ & 165 & 37.97 \\
\hline $\begin{array}{c}\text { Co-Mg-Al catalyst } \\
\text { assisted low } \\
\text { temperature plasma }\end{array}$ & 197 & 25.94 \\
\hline
\end{tabular}

\section{Conclusions}

A series of mixed metal oxide catalyst with different metal species was successfully prepared by coprecipitation and hydrothermal method. The mixed metal oxide catalyst with high crystalline and good structure can be prepared when the molar ratio was in the range of $0: 2: 1$ to $2: 0: 1$ and the reaction temperature is $80-100{ }^{\circ} \mathrm{C}$. The catalytic performance test results show that toluene can be removed from 266ppm to 226ppm by single low temperature plasma at room temperature. The concentration of toluene decreased significantly and the catalytic performance improved when the low temperature plasma was assisted by mixed metal oxide catalyst. The order of catalytic activity of toluene removal by different kinds of mixed metal oxide is as follows: $\mathrm{Zn}-\mathrm{Mg}-\mathrm{Al}>\mathrm{Cu}-\mathrm{Mg}-\mathrm{Al}>\mathrm{Mg}-\mathrm{Al}>\mathrm{Co}-\mathrm{Mg}-\mathrm{Al}$.

\section{Acknowledgment}

Authors wishing to acknowledge financial support from Guangdong Province Characteristic innovation project of colleges and universities (natural science) "research on catalytic synergistic removal of volatile organic pollutants" (2019).

\section{References}

1. X. Tianshan. Beijing Fores. Univ. (2020)

2. Z. Qian, G. Yunli, J. Na, S. Chunfeng, M. Degang, L. Qingling. Prog. Chem. 12 (2016)

3. L. Juan, W. Shuang, L. Jinping. Taiyuan Univ. Tech., 50, 4 (2019)

4. W. Xiao, L. Shengyu, H. Tingyu, K. Minhui, W. Qingqing. J. Environ. Engin. 10 (2017)

5. H. C. B. Hansen and C. B. Koch, Appl. Clay Sci. 10, 5 (1995)

6. W. Mei. Suzhou Univ. (2016) 